Conference

Circuit

\title{
Spring and diversity in the air of ACRL conference
}

\section{ACRL's Sixth Conference receives bighest rating ever}

unny skies and beautiful spring weather greeted the over 2,000 librarians and vendors representing every state and seven foreign countries attending ACRL's Sixth National Conference, "Academic Libraries: Achieving Excellence in Higher Education," in Sait Lake City, April 12-14, 1992. Conference-goers enjoyed the intimacy and convenience of ACRL's National Conference and gave high marks to the theme speakers, the presented papers, and the quality of the exhibits (see "Sixth conference a success" sidebar).

Diversity was the watchword of the conference as keynote speakers addressed civil rights, women's studies, and the information explosion. Cooperation also played an important part in ACRL's 6th National Conference as ACRL conference planners worked with the Utah Li-

Left to rigbt: Three of ACRL's theme speakers: Linda Crismond with Paul Saffo; Altbea Jenkins with Catharine Stimpsom; and W. David Penniman

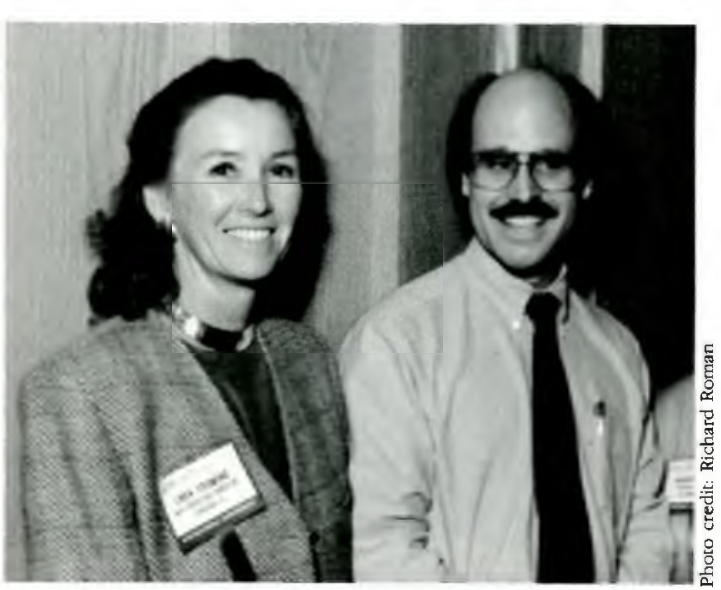

brary Association (ULA) to hold the first ALA division national conference in conjunction with an ALA chapter meeting.

Those attending the conference were also fascinated by the library facilities at the Mormon's renowned Family History Library. Over 300 librarians jammed the auditorium for an introduction to and tour of the facility late in the afternoon on the last day of the conference. Of particular interest was FamilySearchô, the user-friendly computerized system of genealogical information available in the library. Banks of compact-disk workstations await the visitors who line up before the doors open at $7: 30$ a.m. to have first crack at the equipment. The center receives over 800,000 visitors each year.

Keynote speaker Julian Bond indicted recent Republican administrations as he gave conference-goers a history of civil rights in the U.S. He highlighted the successes of the $1960 \mathrm{~s}$ and the failures of the 1980s. "And for those Americans whose skins are black or brown, the poverty rate went up while median family income went down. . . . In 1969, three-fourths of all black men were working; by the 80's end, only $57 \%$ had a job. For these families, it was never morning in America. The only shin- 
ing points of light they see are daylight through the cracks in their walls."

In his eloquent way Bond described how another generation's dreams of equality had been "set aside in favor of defense spending, balanced budgets, and corporate domination of the economy" and then listed some of our problems:

"We've let our infrastructure, our streets and roads and bridges, fall apart.

For many in the middle class, only mom's paycheck keeps them out of the poorhouse.

Most Americans can't afford to be sick, can't pay the doctor when they are.

Yet we seem to find more than enough to feed the military machine.

In just three years in the 1980s we spent more than $\$ 1$ trillion dollars on military expenditures."

\section{"Conan the Librarian"}

"Conan the Librarian type of access-lots of rules and show no mercy" is something that Paul Saffo, research fellow at the Institute for the Future, predicts will change as technology continues to evolve. Rather than myriad search protocols that must be mastered, Saffo hopes for a smoother, friendlier interface. He explained that technology will enable these changes but will not cause change. Quoting Mark Twain's "I'm all for progress; it's change I'd rather avoid," Saffo examined change and explained that change is slow- "most ideas take about 20 years to be an overnight success." He cited the invention of the mouse (the computer pointing device) and windows (a computer display feature) in the early 1960s which did not become overnight successes until the ad- vent of desktop publishing in the 1980s. He said that we are currently on the cusp of two revolutions - the print revolution which occurred over four centuries, and the electronic revolution which has happened in the last 20 years.

\section{As someone who bas never won anytbing, I was amazed at my good fortune, and took pleasure in every aspect of the trip.}

-Deborah C. Masters

George Washington University

Winner of an all-expenses-paid trip to ACRL's 6th National Conference

Saffo offered these predictions for the future: in the short run we will use more paper than ever with the advent of the fax machine and the photocopier; the dominant form of storage will be electronic; the communications laser will be the medium of the 1990s; standalone personal computers (PCs) will not play a long-term role and will likely not last out the decade; PCs will be replaced with connected workstations and a number of information appliances that are cheap, special purpose, and powerful will be developed; libraries will be everywhere but nowhere ("they will be less of a place and more of a space"). Saffo described librarians as swimming in the sea of an information revolution and urged them to take a step back and look at the revolution and its implications from a distance.
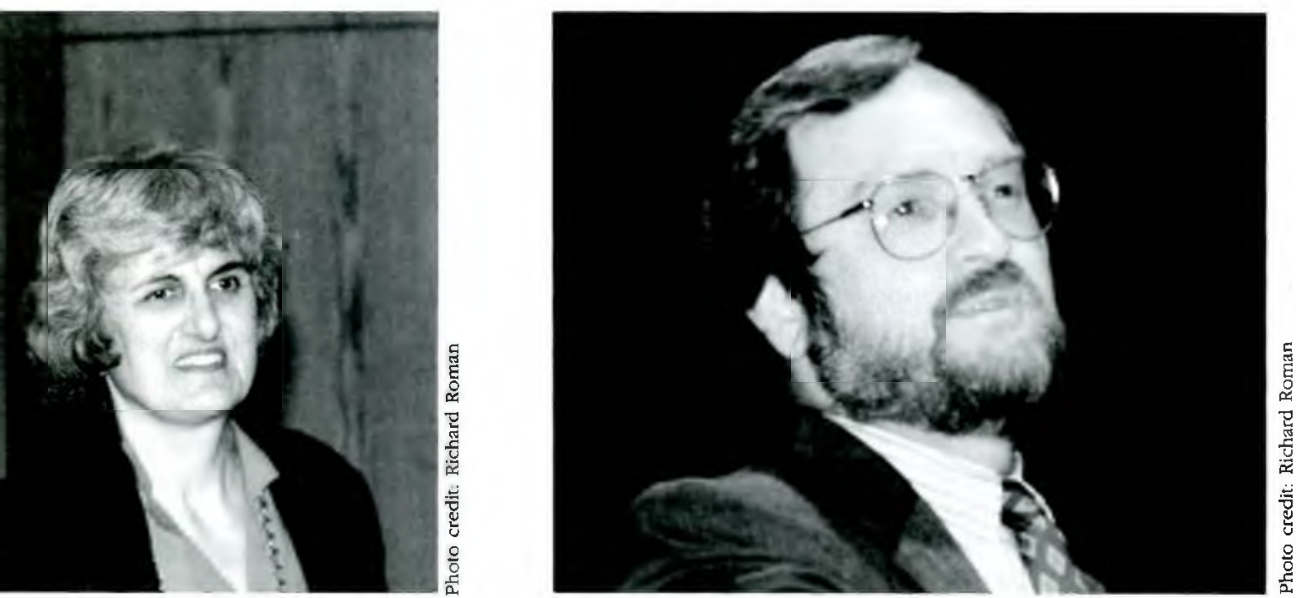


\section{A "cook's tour"}

Sporting a "Never Again: Safe and Legal Abortion for All Women" button, feminist Catharine Stimpson, dean of the Graduate School-New Brunswick and vice provost for graduate education at Rutgers, acknowledged the controversy surrounding the selection of Salt Lake City as a conference site and pledged to place a tithe on her honorarium and donate it to the NOW legal defense and education fund. Stimpson gave a "cook's tour of women in higher education" wondering if women and men "did not have different relations to intellectual freedom and information." Stimpson stated that "contemporary feminism structured itself as an educational reform movement with five goals: 1) improving child-rearing and socialization practices; 2) organizing small 'consciousness-raising' groups; 3) attacking the media; 4) creating cultural alternatives; and 5) transforming the sites of formal education from child-care to research centers."

\section{Sixth conference a success}

ACRL's Sixth National Conference in Salt Lake City received the highest-ever evaluation for an ACRL National Conference and was attended by 1,660 librarians and 581 exhibitors. "The attendees rated the conference 3.85 on a 5 -point scale with 5 being excellent," said conference chair Joseph A. Boissé, University of California, Santa Barbara. General session speakers, exhibits, and the Salt Palace facilities received the highest marks.

When asked if they planned to attend the next ACRL National Conference, March 29-April 1, 1995, in Pittsburgh, 77\% of the Salt Lake attendees said yes. As one participant wrote, "This was a great conference. Attending ACRL National Conferences will be a priority for me from now on."

Although the financial report for the conference will not be available for a few months, conference planners are projecting a financial success.

ACRL's last National Conference in the western U.S. was in Seattle in 1984. A total of 1,754 attended the conference. The 5 th ACRL National Conference in Cincinnati in 1989 attracted 2,735 people.
Stimpson reported progress in a number of areas citing the disappearance of overt discrimination, awareness of sex discrimination, antidiscrimination laws, institutional policies against discrimination, an increase in the numbers of women entering colleges and universities, and more equitable hiring.

Stimpson said that it is not surprising that women's studies has opposition and that this opposition keeps it on its toes. She felt that women's studies "offers the information society several goods: a moral vision of a just and equitable educational community" and a "rich, gutsy, cross-disciplinary menu of ideas about sex and gender."

\section{More on change}

Also addressing change, W. David Penniman, president of the Council on Library Resources, stressed that libraries must adapt to survive. Penniman called upon librarians to change the way they measure success and to focus on delivery of information rather than warehousing of information. He said that libraries must be held accountable for the benefits and costs of services they provide and identified four areas in academic librarianship that need research: human resources, economics of information services, infrastructure. and access and processing.

The full text of the remarks of the theme speakers will be published in the conference proceedings, Academic Libraries: Achieving Excellence in Higher Education, available from ACRL in August 1992. Full conference attendees will be mailed a copy.

The following session summaries (arranged by topic) are the first of a two-part report; the second part will appear in the July/August issue. Summaries are provided thanks to a legion of CERL News reporters.

Ed note: The editor thanks the many librarians who provided conference reports and regrets that due to space limitations we were unable to use them all.

\section{Academic librarianship}

Nancy Deyoe, Margaret Fast, and Sue Weiland, all of Wichita State University, described the "collegial system" that has replaced the traditional organizational system during "Collegial Leadership and Management: An Example in a Cataloging Department." All catalogers and paraprofessional employees participate and the catalogers share collective responsibility for all departmental activities. Catalogers take turns 
serving as department coordinator and overseeing the day-to-day work. Effective communication among staff members at all levels with information flowing vertically and horizontally is the key to effective collegial leadership and management. Paraprofessionals appreciate being informed. An initial analysis of the collegial management system conducted in 1991 found that "catalogers are more responsive and operate more as a unit." Morale improved significantly and "the team spirit improved the overall working environment."-Laurie S. Linsley, Seminole Community College, Sanford, Florida

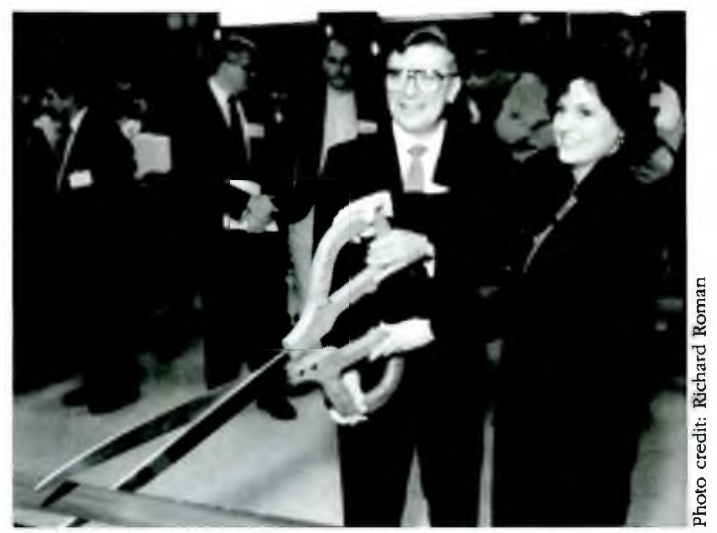

Conference chair Joseph Boissé and ACRL President Anne Beaubien cut the ribbon to open the exhibits

\section{Administration}

"Beyond the Survey: Using Market Research Techniques to Improve Library Services and Collections" examined Xavier University Libraries' (Ohio) use of focus groups, market survey techniques, and the principals of TQM (Total Quality Management) to continuously improve library services. Prompted by the comments from the online "suggestion-box" of the new OPAC and a strong commitment to service, the public services staff did research on customer service which lead to many references to TQM, a management concept applied in industry. In order to determine customer satisfaction, an important factor in TQM, 17 stratified focus groups were conducted and a campuswide survey questionnaire was formulated. Faculty member Bob Ahuja served as a technical consultant in constructing the focus groups, training the leaders, developing and administering the survey. Although this was a much greater undertaking than first envisioned, the information and excellent PR was well worth the effort. The library learned what the "customer" wanted, made several "quick fixes," and obtained valuable data for long-range strategic planning, not to mention a solid collection of books on TQMAdeane Bregman, Boston College

Patricia Larsen, University of Northern Iowa, began her discussion of "The Age of Re- . . . Re-thinking, Re-defining, Re-designing Library Structures" by stating that libraries are still hierarchical and slow to change as a result of our fear of change, uncertainty about what change will bring, and complacency. She proposed one systematic approach to change and suggested that "jobs should be designed as well as pos-

sible to meet the needs of individuals as well as the organization." She summarized Campion and Thayer's approaches to job design and submitted a different job characteristics-based model in which the organization recognizes and builds on what the individual brings to the job.-Jean Parker, St. Olaf College

\section{Bibliographic instruction}

Lynne Fox and Jeffrey Bauer, University of Northern Colorado, described the application of instructional design techniques to bibliographic instruction in "Be a One-shot B.I Hotshot." They discussed the four stages of instructional design: 1) front-end analysis to ascertain the current status of the learning audience's skills and interests; 2) the setting of instructional goals and objectives describing learners and the desired outcome behavior under specified conditions and degrees; 3) designing the instructional package, with consideration to learning styles (aural, visual, and kinesthetic) and learner characteristics (e.g., traditional vs. nontraditional), and the concrete steps involved (e.g., gain the attention of the audience, inform the learners of the objectives, stimulate recall of prior learning, etc.); and 4) evaluating and revising the instruction. Bauer urged BI librarians to focus on one of the four components at a time to improve their instructional sessions.-Anne May Berwind, Austin Peay State University, Clarksville, Tennessee

In "Assessing the Need for Bibliographic Instruction in Honors Sections of Freshman Composition," Marjorie Warmkessel of Millersville University reported that at the be- 


\section{Missed the Conference? Don't Miss Out!}

H

ere is your chance to hear important programs on audio cassette recorded at the Association of College Research Libraries Sixth National Conference.

Explore new developments in college and research libraries and librarianship while driving -at home - in the office - wherever and whenever it suits you.

Many of your colleagues from across the nation share insights on the latest developments and trends in the profession. Here is a sampling of the popular topics that are available:

ACRL 206 Diversifying the Academic Library to Meet the $\$ 12.00$ Challenges of Economic Development; Systemic Planning in Small Academic Libraries: Does it Make a Difference?

ACRL 226 Contemporary Sources for Collection Evaluation $\$ 12.00$ and Planning

ACRL 235 Women, the Information Society, and Freedom $\$ 12.00 \quad$ (Catherine R. Stimpson)

ACRL 236 Bibliographic Instruction in the Electronic $\$ 12.00 \quad$ Environment: Incorporating Recent Cognitive Theories of Learning

ACRL 258 The Impact of New Electronic Resources on the $\$ 24.00$ Ecology of the Library: Funds, Collections, Services and Staff

There are more than $\mathbf{5 0}$ programs available on audio cassette, most priced at \$12. For a complete order form, and additional information, write: ACRL AUDIO CASSETTES, c/o Teach'em, Inc., $160 \mathrm{E}$. Illinois Street, Chicago, IL 60611. Or call toll free: 1-800-225-3775 and ask the operator to send you an ACRL cassette order form.

\section{Make Sure You Don't Miss Out!}

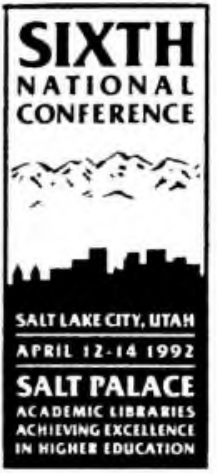


ginning of the semester students were frustrated by not being able to master the complexities of the library after their first visit. She identified four major stumbling blocks: the size of the library building itself, the library's confusing system of organization, a negative impression of the library often based on a "baci experience," and an unwillingness to ask for help. As one student noted, "Sometimes I get a little bit intimidated because I don't know where everything is and I don't like to ask and sound like an idiot." Warmkessel's study confirmed earlier findings that "students in honors programs do not necessarily know any more about libraries than other college students." After BI sessions, however, attitudes toward and comfort with the library changed dramatically. One typical response noted that the presentation had "increase[d] my knowledge of where to go and what to look for. . . . At least I am no longer hesitant to ask for help when I need it!"

In "First Things First," Mary George of Princeton, using examples from the Persian Gulf War, demonstrated her approach to teaching students the differences between primary and secondary sources. She first defined a source as "the tangible container of a phenomenon." She then identified nine "angles" that could be used to evaluate sources: how close a source is to the phenomenon it contains, the unique perspective of each person who either records or explores it, the purpose of those employing the source, the researcher's audience, the source's actual content, the time elapsed since the source's creation, how the source has been transmitted, the source's reliability, and the availability of the source. Using these rools, George has the students examine a wide range of categories-such as diaries, memos, interviews, autobiographies, histories, editorials, opinion polls, and cartoons - to determine what kind of source they are--Nicholas Burckel, Washington University

Barbara Fister, Gustavus Adolphus College, drew parallels between the fields of composi- tion and bibliographic instruction during "Common Ground: The Composition/Bibliographic Instruction." Commonalities included their lengthy histories as topics of inquiry, their similar niches in the academy, their emphases on transferable skills, and their unique ability to see academia from a student perspective. She then described three approaches to writing instruction: the writer/researcher mode which focuses on writing as a form of discovery and uses journaling and freewriting as techniques; the process mode which requires extensive prewriting and revision and in which the process of writing is as important as the end product; and the audience/context mode which involves collaborative learning, peer review, and writing across the disciplines. Applying these same terms to the field of bibliographic instruction, she then gave examples of current emphases in each area: the emphasis on lifelong learning skills and information literacy parallels the free-writing mode; emphasis on search strategies and examining the affective side of research parallels the process mode; and emphasis on collaborative learning and discussing the structure of literature in various disciplines parallels the audience/context mode. Fister urged more collaboration with colleagues who teach writing by reading journals in the field of composition and initiating discussion with colleagues.Kris Huber, St. Olaf College

\section{Collection management}

As collection budgets shrivel in the 1990s, interest in collection evaluation intensifies, which explains the high turnout for this session, on "Contemporary Sources for Collection Evaluation and Planning."

Blackwell North America's R. Charles Wittenberg discussed the increasing amount of library-demanded and vendor-provided collection data. He said, "This data is sand, mountains of sand. Collection policies are dream castles. How does one get made into the other? We're in an age where we need to be producing cunning shovels and clever buckets to deal with this." 


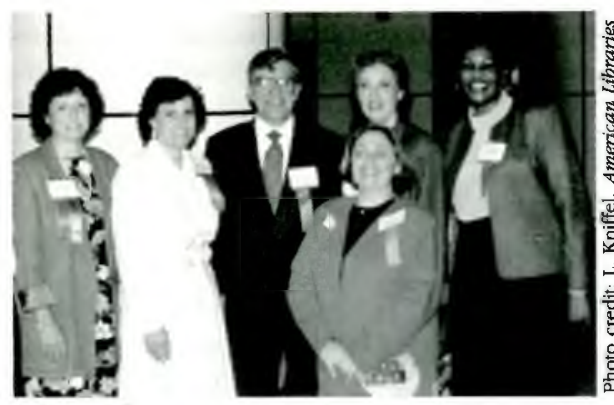

ACRL leaders and staff (from left): vice-president Jacquelyn McCoy, president Anne Beaubien, conference chair Joseph Boissé, past-president Barbara Ford, deputy executive director Cathleen Bourdon, and executive director Althea Jenkins.

American University's Tricia Vierra Masson spoke about combining the analyses of collection content and use. The Washington Research Libraries Consortium uses the National Shelflist Count and incorporates circulation data to facilitate comparisons within and outside the consortium. She raised the possibility of a consortium approval plan.

Emory University's Kathy Teszla discussed her library's development of a comprehensive collection development statement (with strong university administration support) in response to faculty criticism of the collection. Using the National Shelflist Count, data was obtained to serve as a guide in budget allocations. Also, a dollar figure was determined for moving each subject from its current collection level to the desired level. The library experienced increased budget allocations and improved relations.

Middlebury College's Joanne Hill had to quickly order materials to meet the needs of a growing Hispanic student population. She generated order lists and bibliographies by searching a variety of Internet-accessible OPACS.Orlando Archibeque, Auraria Library

"Coordinated Collection Development: The Current Impetus" described coordinated collection development programs involving multitype (public, academic, school, and special) library systems. Barbara Allen of the Illinois State Library described how the state of Illinois has supported and funded cooperative assessment and acquisitions of library collections since the early 1980s. Administration is provided by a standing committee, and funding is through the state's Board of Education. The program at- tempts to respond to individual collection needs, with the underlying concept being the development of a truly statewide collection.

Barbara Doyle of Augustana College described the Quad-LINC system in River Bend, Illinois. Quad-LINC shares a cooperative database used for acquisitions decisions by all participating libraries. Attempts are made not to duplicate materials. Collection development has become user-driven as well as cooperative. Administration is also cooperative, with all library directors meeting monthly for shared decisionmaking. Plans call for linking all local systems with the statewide system.

The New York METRO system described by Anthony Ferguson of Columbia University, serves as an ILL clearinghouse, provides workshops and training sessions, distributes automation funding, and sponsors cooperative action programs. Some attempts at cooperative collection development have met with only limited success. The main barriers to cooperation among members are competitiveness, the desire to retain autonomy, and valuing ownership over sharing.

Two countywide cooperative collection development projects in Washington described by Dal Symes of Western Washington University, resulted in successful LSCA grant applications. One involved development of video collections, the other strengthening local law collections. The latter also involved adding holdings to a WLN database, and both involved the creation of union lists.

There was a consensus among the panelists that mutual trust is an essential element for cooperative collection development. "Small is better" seems to be the operating principle for establishing cooperation.-Wendy Knickerbocker, Rbode Island College

ACRL's African American Studies Librarians Section examined the role of "African-American Studies in Libraries." Howard Dodson, chief of the Schomburg Center for Research in Black Culture, argued for replacing the vindicationist model (where the purpose is to defend people of African descent against charges of racial inferiority and historical and cultural insignificance) with a model promoting the role of Africans and African-Americans in this hemisphere. Dodson suggested expanding the scope of the collections and thinking to become more inclusive of resources related to the African diaspora (the dispersion of people of African 
descent from their homeland). He also contended that African-American Studies librarians must establish collaborative efforts to share resources and that it is important to take full advantage of computerized and other electronically formatted technologies to make individual collections accessible and available to those who have need to use them.-Michael Walker, Vinginia Commonwealth University

\section{Community colleges}

Jimmie Anne Nourse and Rudy Widman, (Indian River Community College), recipients of the 1991 ACRL Community and Junior College Libraries Section Achievement Award, advocated "Aggressive Teaching for Information Literacy in High-tech Times." Nourse defines information literacy as "knowing how to find information, evaluate it, and use it effectively." She characterized the 50-minute bibliographic instruction presentation as passive teaching. Credit courses, such as the ones offered at Indian River Community College (IRCC), represent proactive, aggressive teaching.

The IRCC Learning Resources Center developed three, one-credit-hour, high-technology library instruction courses and packaged them as computer science courses. The courses were developed to help students keep abreast of changes, to prepare students for university work, and to enhance necessary lifelong learning skills. Nourse and Widman stressed that librarians need to be viewed as educators. The community college library/learning resource center is fertile ground for credit library programs because community college librarians are teaching faculty, rather than research faculty.

To complement the course developed at IRCC Nourse and Widman have written a textbook called Electronic Access to Information. (Dubuque, Iowa: Kendall/Hunt, 1991; \$18.95), that may also be used as a stand-alone reference.-Laurie S. Linsley, Seminole Community College, Sanford, Florida

\section{International librarianship}

Five librarians and library educators from around the world spoke during "Research and the Academic Librarian: A Global View." Colin Taylor of Australia said that much of the research by university librarians in Australia and New Zealand is of the developmental "try it and see" type. Librarians need to better document and promulgate their achievements to gain recognition as a legitimate area for research funding.
Ludmilla Kozlova of Russia reviewed the history of research in her own country. During the 1990s, the research emphasis is on the "social role of $\mathrm{l}$ braries in conditions of renovation of the society, book and information cultures of the population, library services for the support of the social rehabilitation, automation of library technologies, and the development of librarianship towards the 21st century." She mentioned that inadequate budget allocation for libraries - including poor salaries for libratians- keep many talented people away from the profession.

P. B. Mangla of India spoke about the research capabilities of South Asian librarians. He described the role of the late S. R. Ranganathan under whose guidance the libraries and research made progress in India. Mangla asserted that the quality of research needs to be improved, more dynamic librarians be hired, and more funds be allocated to academic libraries for research purposes.

James M. Ng'ang'a of Kenya traced the history of academic institutions and the central role of university libraries in Africa. He said librarians are expected to undertake research due to the nature of their academic appointment. Financial support and encouragement is given to all librarians by universities to undertake research and publish. Still the number of librarians engaged in research is very small and the use of technology in research has been minimal. Some of the reasons for this include inadequate staff, poor facilities, lack of resources and current research material, and not enough funds for academic librarians.

Stephen W. Massill of England told the audience about research in Europe with emphasis on the United Kingdom. In his view, research and publishing by academic librarians in Europe is voluminous. "Trends in academic librarianship have altered the way in which staff

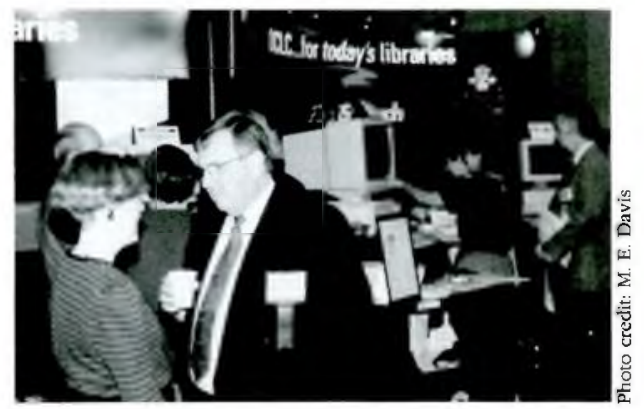

Conference-goers chat at one of the over 250 exhibit booths at the 6 th National Conference. 
carry out their academic role," he said. Scholarly work is respected and honored by faculty but still not well rewarded by the employers.

It was clear from all presentations that academic librarians worldwide are still not fully engaged in research due to various reasons including lack of interest, encouragement, funds, and rewards-just like their counterparts in the United States.-R. N. Sharma, University of Evansville, Indiana

\section{Reader services}

In "Scholarly Use of Academic Reference Services," William G. Jones, University of Illinois at Chicago, claimed that scholars are not heavy users of general reference services. Humanities scholars in particular rely on research skills learned in their graduate preparation and are loathe to look upon librarians as useful for their research, except in the case of interlibrary loan. Scholars value literature sources recommended by colleagues, citation in books and joumals, and sources such as newsletters, book reviews, publisher's ads, and specialized bibliographies. Gaps occur in their knowledge of the existence of databases, their use of comprehensive indexes, and their use of librarians' knowledge beyond deciphering citations.

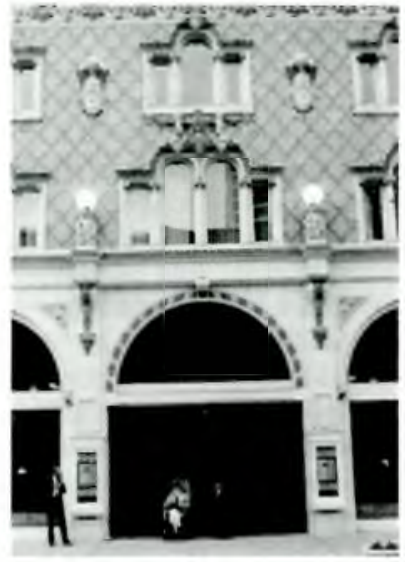

Program participants attended a reception at the Capitol Theatre in Salt Lake City. research; that librarians must go to scholars directly rather than expecting them to queue up at reference desks; and that librarians must conceive of service to scholars as a way of contributing to a community of learning.-Jobn Scbmitt, Colorado State University

"What Happens When You Eliminate the Reference Desk?" by Virginia Massay-Burzio examined the consequences of eliminating the "age-old tradition" of the reference desk in the main library at Brandeis University. She referred to the reference desk as "an impedimentor not a facilitator" and stated that it is "based on the fantasy that we can serve all of the people all of the time." We have overstressed the "sacred cow" of user access to librarians to the detriment of user needs. At Brandeis the reference desk has been replaced by an information desk staffed by graduate students who offer directional and "brief answer" (2-3 minute limit) assistance and refer on more difficult questions (about $40 \%$ of the total). The referred questions go to a Research Consultation Office, open 52.5 hours per week, with each librarian having office hours 2 hours per day. Librarians and students alike have positive feedback on the new system: 1) patrons feel they are getting a special and valuable service and enjoy the individual attention; 2) librarians have a greater job satisfaction rating; and 3) a high quality of service is provided with the most judicial use of staff._Jacqueline Borin, California State University, San Marcos

"Serving the Disabled Patron" offered handouts and practical tips about the Americans with Disabilities Act and discussed how our libraries should offer services to disabled patrons. Katy Lenn, University of Oregon, stated that "the real impact may be on public libraries," but on college campuses, "disabled students and faculty will become much more vocal."

The program emphasized that libraries need to make reasonable accommodations and that they must provide truly integrated programs and services for disabled patrons. Some suggestions given were: establish a liaison posi- 
tion; organize the documentation generated by this law and its interpretation; develop a master plan; establish good relations with other campus offices and other resource people; join mailing lists; write policy statements; seek staff development programs; and establish emergency procedures.

Each library should try to survey the campus population to determine the numbers of disabled. Then meet with these students and offer a tour of your facility. Review the adaptive aids that you own and your plans for future purchases.

Final tips included checking furniture, signage, and the types of alarm systems that your library has-they may not be adequate. Also, collection development plans should include the purchase of materials for the disabled. "Be prepared and knowledgeable," was the lesson of the program.-Katby Sanders, University of Arkansas, Little Rock

\section{Technology}

"IRIS: The Intelligent Reference Information System-Evaluation of a CD-ROM Network with an Associated Expert System," presented by Kimberley Spyers-Duran and Kathleen Gunning, examined ways of dealing with the proliferation of information. Mooer's Law predicts that the number of information sources will double every $21 / 2$ years, and reference librarians have found CD-ROM databases as both an example of this phenomenon and a tool to control access to this abundance of information. The University of Houston Libraries has exploited the technology by providing simultaneous access for multiple users to 19 databases via a local area network and CD-ROM servers. In addition, a locally developed expert system-Reference Expert-provides frontend assistance to the user in determining which reference sources (both print and CD-ROM) are available and germane to the topic of the search request in terms of content type, format, and subject.

Use of the ten workstation CD-ROM LAN and Reference Expert in the Electronic Publications Center (EPC) (located in proximity to the Reference Desk) increased from 25,000 during the first year of implementation to 77,000 in the second year. User reactions were assessed by use statistics and user perception surveys which showed users reacted positively to CDROM over print indexing sources, but found inconsistent command structures between da- tabases problematic. About half of the respondents reported that they discovered information sources new to them by using Reference Expert. Gunning noted that increased demand for terminal use made 30-minute reserved search session scheduling necessary, and planning is underway for a two-phase expansion of the number of terminals and databases to be made available. Space planning, staffing patterns, and vendor lease arrangements for multiple access use of CD-ROMs are related concerns stemming from the growth of this network. True to Mooer's Law, the library anticipates sixfold growth three years into the program, and projects the need for 200 stations in the next decade.-Victoria M. Peters, University of Arizona Graduate Library School

E. Paige Weston, in her program "An OPAC for Every Public," stated that recent efforts to personalize datafiles stem from attempts to control the workplace. "What do online users wish they could control?" Theme items: the telecommunications environment; the types of search strategies needed; the vocabulary they enter; the data in a system; the display of information in a prescribed, demanded style; finally, the data export options.

Weston called for a great deal more research into how libraries can customize their OPACS to create more flexible tools. "The public is going to come to expect this [customizing of the OPAC]," she stated.-Katby Sanders, University of Arkansas, Little Rock

\section{ACRL thanks colleagues}

ACRL thanks all of the companies and corporations that contributed to the success of its 6th National Conference in Salt Lake City. Special thanks to ACRL Colleagues:

\section{Summa cum laude:}

Baker \& Taylor Books; EBSCO

\section{Magna cum laude:}

Blackwell; Dynix; Faxon; IBM

\section{Cum laude:}

Academic Book Center; Ballen Books; Harrassowitz; Information Access; Midwest Library Service; UMI; VTLS, Inc.; Yankee Book Peddler 